\title{
PEMIKIRAN NEO-SUFISME SYAIKH AHMAD Al-MUTAMAKKIN
}

\section{Manggara Bagus Satriya Wijaya, ${ }^{1}$ Sariyatun ${ }^{2}$}

\author{
Pascasarjana Universitas Sebelas Maret, Surakarta - Indonesia
}

e-mail: 1manggara.b.s.w@gmail.com; 2sari_fkip_uns@yahoo.co.id

\begin{abstract}
This article intends to reveal Syaikh Ahmad al-Mutamakkin's neo-Sufism thoughts and his role in campaigning for the renewal of Islamic thought and changes in the social order of people's lives in Java in the 18th century. The discussion will focus on the domain of epistemological conflicts that legitimize al-Mutamakkin as a controversial contemporary Sufi. Historical exploration and appreciation will be more emphasized to fully look for facts about the teachings developed by al-Mutamakkin. This research is historical research using a hermeneutic approach to study and trace the artifacts of al-Mutamakkin's thoughts. This study found that al-Mutamakkin was a reformist figure who played an active role in upholding Islamic teachings as a universal religion and eternal through an eclectic and conformist approach to the existence of local wisdom values (local wisdom). As a reformist figure who carried the breath of renewal of the teachings of Sufism (neo-Sufism), al-Mutamakkin strongly criticized the teachings of Sufism developed by the Mataram elite. The king-Sufi political conception commonly adopted by the court elite in the 18th century in alMutamakkin's perspective was a form of betrayal of the teachings of Sufism. Therefore, in his perspective, the teachings of Sufism must be improved and adjusted to the proper khittah, namely as an instrument of self-formation and development of perfect human beings (insān kāmil) which is adjusted and guided by Allah's revelation and the Prophet's Sunnah.
\end{abstract}

Abstrak: Artikel ini hendak mengungkap pemikiran neo sufisme Syaikh Ahmad alMutamakkin dan perannya dalam mengkampanyekan pembaharuan pemikiran Islam dan perubahan tatanan sosial kehidupan masyarakat di tanah Jawa pada abad ke-18. Pembahasan akan difokuskan pada ranah konfik epistemologis keagamaan yang melegitimasi al-Mutamakkin sebagai seorang sufi heretic yang penuh kontroversi. Penulusuran dan penghayatan historis akan lebih ditekankan untuk sepenuhnya mencari fakta mengenai ajaran yang dikembangkan oleh alMutamakkin. Penelitian ini adalah riset sejarah dengan menggunakan pendekatan hermeneutika untuk mengkaji dan menelusuri artefak pemikiran-pemikiran alMutamakkin. Penelitian ini menemukan bahwa al-Mutamakkin adalah seorang tokoh reformis yang berperan aktif dalam menegakkan ajaran Islam sebagai agama universal dan eternal melalui pendekatan eklektik dan konformis terhadap keberadaan nilai-nilai kearifan lokal (local wisdom). Sebagai tokoh reformis yang mengusung nafas pembaharuan ajaran sufisme (neo-sufisme), al-Mutamakkin sangat mengkritisi ajaran sufisme yang dikembangkan pihak elit kerajaan Mataram. Konsepsi politik raja-sufi yang lazim diterapkan elit istana pada abad ke18 dalam perspektif al-Mutamakkin adalah bentuk penyelewangan terhadap 
ajaran sufisme. Menurutnya, ajaran sufisme harus diperbaiki serta disesuaikan dengan khitah yang semestinya, yakni sebagai instrumen pembentukan diri dan pembangunan manusia sempurna (insān kāmil) yang disesuaikan serta berpedoman pada wahyu Allah dan Sunnah Nabi.

Keywords: neo-sufism; Syaikh Ahmad al-Mutamakkin; critic of religious epistemology; cleric

\section{A. Pendahuluan}

Islamisasi merupakan sebuah proses konversi keyakinan masyarakat menjadi Islam. Secara kultural, proses islamisasi di tanah Jawa kian masif sejak para sufi dengan beragam metode dakwahnya menyebarluaskan ajaran Islam pada akhir abad XVIII. ${ }^{1}$ Salah satu metode dakwah yang sering dipakai para sufi untuk kepentingan islamisasi ialah tasawuf atau sufisme. Kata tasawuf bisa diartikan sebagai moralitas dalam Islam untuk mencari hakikat kesempurnaan rohani dan mengenalkan Dzat Tuhan dengan segala kesempurnaannya, sebagaimana pendapat Ibn Qayyim dalam Madārij al-Sālikīn, al-Kattani dan juga Ibn Khaldun. ${ }^{2}$ Dalam sejarah pemikiran Islam, kemunculan ajaran tasawuf dan prakteknya sendiri sebenarnya sudah ada sejak zaman Nabi Muhammad yang berakar dari dorongan internal yang bersumber dari Islam itu sendiri (baik alQur'an dan al-Hadis) serta dorongan ekternal yang melatarbelakangi munculnya tasawuf. 3

Keberhasilan proses islamisasi di Jawa telah menyebabkan para sufi dan ajaran tasawuf (sufisme) mendapat tempat di hati masyarakat kala itu. Selain itu, keberhasilan proses islamisasi juga telah membuat para sufi mendapat kedudukan istimewa di dalam sistem politik kerajaan Islam di Jawa sejak akhir abad XV. Namun hubungan harmonis antara para sufi dan raja dalam sistem politik di Jawa ternyata tidak bertahan lama. Sejak abad XVIII atau saat diberlakukanya konsep Raja-Sufi pada masa pemerintahan Pakubuwana II di Mataram, harmonisasi antara para sufi dan elit istana merenggang. Memburuknya relasi antara raja dan para sufi disebabkan oleh perbedaan paradigma keduanya dalam memandang ajaran dasar sufisme (tasawuf). Para sufi meng-

\footnotetext{
${ }^{1}$ Merle Calvin Ricklefs, Mengislamkan Jawa: Sejarah Islamisasi di Jawa dan Penentangnya dari 1930 sampai Sekarang (Jakarta: Serambi, 2013), 5.

${ }^{2}$ H. M. Amin Syukur, Tasawuf Sosial (Yogyakarta: Pustaka Pelajar, 2004), 10.

${ }^{3}$ Hermansyah Hermansyah, "Neo-sufisme (Sejarah dan Prospeknya)," Khatulistiwa 3, no. 2 (2013): 113-20, https://doi.org/10.24260/khatulistiwa.v3i2.217.
} 
anggap bahwa dalam konteks politik, ajaran sufisme telah digunakan raja untuk menekankan kebesaran serta melekatkan sifat-sifat supranatural atau dengan kata lain ajaran sufisme telah disalahgunakan untuk mereproduksi khazanah keagamaan pra Islam yang bersifat pantheistis. ${ }^{4}$ Perbedaan paradigma tersebutlah yang menimbulkan gesekan antara raja, dengan para sufi yang berlatar belakang kultural.

Konflik antara elit istana dan para sufi berlatar belakang kultural terekam jelas dalam Serat Cebolek yang ditulis pada masa pemerintahan Pakubuwana II (1726-1749) M. ${ }^{5}$ Isi Serat Cebolek mengisahkan dengan jelas bagaimana latar belakang hingga penyelesaian konflik antara ulama sufi keraton yang diwakili Ketib Anom Kudus dengan Syaikh Ahmad al-Mutamakkin yang dianggap menyebarkan ajaran sesat. Di akhir cerita, Serat Cebolek menegaskan bahwa tuduhan heretic (menyimpang) yang disematkan kepada Syaikh Ahmad alMutamakkin memang benar adanya. Selain itu, Serat Cebolek juga membeberkan berbagai kesalahan dan kelemahan ajaran Syaikh Ahmad al-Mutamakkin serta kekalahannya dalam perdebatan dengan Ketib Anom Kudus mengenai penghayatan cerita Dewaruci dalam perspektif sufisme. Dengan demikian, seperti yang ditegaskan dalam Serat Cebolek bahwa, konflik epistemologis keagamaan yang dimenangkan pihak keraton pada akhirnya semakin memperkuat kedudukan konsepsi raja-sufi dalam kehidupan masyarakat sekaligus mengikis pengaruh ulama-ulama sufi yang berada pada tataran kultural.

Tulisan ini secara mendalam akan difokuskan pada ranah konfik epistemologis keagamaan yang melegitimasi Syaikh Ahmad al-Mutamakkin sebagai seorang sufi heretic yang penuh kontroversi. Penulusuran dan penghayatan historis akan lebih ditekankan untuk sepenuhnya mencari fakta mengenai ajaran yang dikembangkan oleh Syaikh Ahmad Mutamakkin. Sebagai seorang sufistik, Syaikh Ahmad al-Mutamakkin tentunya mempunyai genealogi keilmuan yang cukup berpengaruh terhadap pendekatan dakwah yang ia rintis dalam proses islamisasi di Jawa kala itu. Dari jejak historis diketahui bahwa,

\footnotetext{
${ }^{4}$ Berkenaan dengan pemikiran politik Jawa pada fase ini yang diagitasikan melalui berbagai karya sastra terdapat kesan bahwa sentral raja dalam bangunan politik dan budaya jawa adalah wacana dominan dalam teks-teks Jawa abad XVIII. lebih lanjut lihat: Merle Calvin Ricklefs, The Seen and Unseen Worlds in Java 1726-1749: History, Literature and Islam in the Court of Pakubuwana II (Sydney: Asian Studies Association of Australia in association with Allen \& Unwin and University of Hawaii Press, 1998), 123.

${ }^{5}$ S. Soebardi, The Book of Cabolek a Critical Edition with Introduction, Translation, and Notes: a Contribution to the Study of the Javanese Mystical Tradition (The Hague: Martinus Nijhoff, 1975), 56.
} 
Syaikh Ahmad al-Mutamakkin merupakan seorang ulama sufi yang menyebarluaskan ajaran Islam di wilayah Pati dan sekitarnya. Kendati sempat mendapat stigma negatif dari Keraton Mataram, ajaran-ajaran Islam yang beliau kembangkan hingga kini masih terus dilestarikan oleh generasi-generasi keturunanya. Hal ini dibuktikan dengan banyaknya generasi-generasi keturunan beliau yang berperan sebagai pendiri dan pengasuh di pondok pesantren yang tersebar sewilayah Pati dan sekitarnya. ${ }^{6}$

Pendekatan dakwah yang dilakukan Syaikh Ahmad al-Mutamakkin bersifat dinamis. Pendekatan dakwah semacam ini sepertinya relevan dengan realita yang dialami masyarakat setempat sehingga meminimalisir terjadinya situasi chaos seperti yang didapat pada ekspansi Sultan Trenggono dan Sultan Agung dalam upaya mengislamkan wilayah Blambangan. Dengan kata lain, pendekatan kultural semacam ini cenderung mampu memelihara kearifan lokal setempat sehingga tidak menimbulkan friksi dengan realitas kehidupan sosial budaya masyarakat. Kedinamisan pemikiran keagamaan Syaikh Ahmad al-Mutamakkin memang sangat dipengaruhi oleh rihlah ilmiah yang dilakukanya, sejak berguru pada Syaikh Zayn al-Mizjaji al-Yamani di Yaman pada dasawarsa kedua abad XVIII. Sosok Syaikh Zayn al-Mizjaji al-Yamani sendiri sejatinya merupakan seorang pengembang neo-sufisme peridoe awal. ${ }^{7}$ Dalam sejarah pemikiran Islam, gerakan neo-sufisme yang didirikan di Yaman sejak periode awal abad XVIII memang, bertujuan untuk melakukan kritik dan koreksi terhadap percampuran antara tasawuf dengan ajaran filsafat (tasawuf falsafi) dalam praktik keagamaan. Keberadaan kritik dan koreksi oleh para ulama pengembang pemikiran neo-sufisme sejatinya ialah antitesa terhadap beberapa kasus penyimpangan pendukung tasawuffalsafi dalam beberapa aspek tertentu yang sudah tidak sejalan dengan syari'at Islam. Dengan beberapa tokoh yang terkenal seperti Ibn 'Arabi dengan teori waḥdat al-wujūd-nya, Suhrawardi alMaqtūl dengan teori ishrāqiyah-nya, Ibn Sabi'in dengan teori ittihad, Ibn Farid dengan teori cinta, fana' dan wah̆dat al-shuhūd-nya.

Sesungguhnya, apabila menelisik genealogi keilmuan Syaikh Ahmad alMutamakkin, maka tidak heran jika pemikiran sufisme bentuk baru (neo-

${ }^{6}$ K.H. Thohir Muadz, keturunan ketujuh Syaikh Ahmad al-Mutamakkin dan pengasuh Pondok Pesantren Ar-Raudlah Kajen, wawancara, 8 Maret 2018.

${ }^{7}$ Syaikh Zayn al Mizjaji al-Yamani adalah seorang tokoh berpengaruh dalam tarekat Naqsabandiyah pada abad XVIII. Lihat: Zainul Millal Bizawie, Syekh Mutamakkin: Perlawanan Kultural Agama Rakyat (Jakarta: Pustaka Compass, 2014), 124. 
sufisme) inilah yang sangat mewarnai strategi dakwahnya, dalam menyebarluaskan ajaran Islam di tanah Jawa pada abad XVIII. ${ }^{8}$ Dalam konteks strategi dakwah, pemikiran neo-sufisme terlihat dari upaya Syaikh Ahmad al-Mutamakkin, untuk melakukan perubahan dalam masyarakat melalui anjuran untuk berusaha, belajar, berkarya. dan bekerja keras secara mandiri dari pada menunggu datangnya intervensi dan pertolongan eskatologis dari Tuhan. Kultur pemikiran inilah yang menyebabkan Syaikh Ahmad al-Mutamakkin kemudian selalu menggunakan kisah-kisah inspiratif dalam setiap prosesi dakwahnya. Salah satu kisah inspiratif yang sering dipakai Syaikh Ahmad al-Mutamakkin adalah teks Bimasuci atau Dewaruci. Dalam dunia pewayangan Jawa sendiri, keberadaan teks Bimasuci memang diakui ke dalam jajaran lakon tua. ${ }^{9}$ Dikisahkan dalam lakon tersebut, bahwa Bima saat ditanya mengenai ketuhanan tidak bisa menjawab dan lantas mengalami kebingungan. Di dalam hatinya Bima berhasrat untuk mengetahui asal usul kehidupan (sangkan paraning dumadi) dan tujuan akhir setelah kematian (kasedan jati). Pesan utama teks tersebut terletak pada sisi spiritual, dimana untuk bersatu dengan tuhan ( $m a^{\prime}$ 'rifat) setiap manusia terlebih dahulu diharuskan melalui berbagai tahapan hidup yang tentunya akan menuntun mereka menjadi manusia paripurna (insān kāmil), baik dalam dimensi keimanan maupun dimensi akhlak. Oleh sebab itu, kandungan isi teks tersebut memang dianggap Syaikh Ahmad al-Mutamakkin mampu mereplika perjalanan spiritual masyarakat sehingga mampu mengisi kekurangan platform arsitektur otak manusia dalam ranah ketauhidan.

Keberadaan teks Bimasuci memang lekat dengan dunia tasawuf karena teks ini mencerminkan penghayatan yang begitu mendalam mengenai prosesi pencarian jati diri manusia. Menurut Syaikh Ahmad al-Mutamakkin, karena keterbatasan platform arsitektur otak manusia dalam menyerap pelajaran ketauhidan, maka perjalanan spiritual Bima dalam teks Bimasuci relevan untuk mereplika tujuan hidup setiap individu, terutama dalam proses mengenal hakikat ketuhanan beserta sifat-sifat mutlak yang dimilikinya. Untuk menghayatinya maka diperlukan seperangkat keimanan yang mengarahkan setiap individu untuk selalu bermuhasabah dalam proses perbaikan diri, yang salah satunya dapat diwujudkan melalui pengamalan budi pekerti yang baik (akhlāq

${ }^{8}$ Bizawie, 128.

${ }^{9}$ Definisi lakon tua sendiri memang berasal dari sejarah kelahiran teks tersebut yang masuk kategori awal penggubahan atau sejak era renaissance kesusastraan Jawa mengemuka, yakni pada pertengahan abad XVIII. Lihat: Sri Margana, Pujangga Jawa dan Bayang-bayang Kolonial (Yogyakarta: Pustaka Pelajar, 2004), 78.

JURNAL THEOLOGIA — Volume 29, Nomor 2, Desember 2018 
al-karimah). ${ }^{10}$ Dimensi akhlak inilah yang menurut Syaikh Ahmad al-Mutamakkin, merepresentasikan hubungan antara Allah dan hamba-Nya. Dengan kata lain bagi seorang hamba yang dekat dengan Allah, maka perilakunya pun akan mengikuti suara-suara objektif dari hati nuraninya. Suara-suara inilah yang dalam perspektif keilmuwan sufisme merupakan metaforis dari suara Allah, yang hanya terdapat pada individu-individu yang dekat dengan-Nya. Nantinya suara-suara inilah yang akan menjadi pengontrol seseorang melakukan apa saja, selama ia masih jernih dam belum terkontaminasi oleh keinginan hawa nafsu. Tanpa melangkahi pemahaman syariat islam, sejatinya nilai-nilai penghayatan semacam inilah yang sesungguhnya hendak direkonstruksi oleh Syaikh Ahmad al-Mutamakkin kedalam pemikiran masyarakat.

Beberapa studi yang telah dilakukan terkait dengan sejarah kehidupan Syaikh Ahmad Mutamakkin antara lain kajian Muzairi tentang Serat Cebolek yang ada di Museum Sonobudoyo Yogyakarta, dengan kode W.301 atau C.56. Teks tersebut dialihaksarakan dari huruf Jawa ke aksara Latin, diterjemahkan dari bahasa Jawa ke bahasa Indonesia, dan dianalisis dengan menggunakan konsep-konsep Islam. Isi teks tersebut diinterpretasi sebagai bentuk pembangkangan Syaikh Ahmad al-Mutamakkin (yang mewakili ulama kultural) terhadap arogansi ulama-ulama yang berada pada tataran struktural keraton. ${ }^{11}$

Kedua, pemikiran tasawuf Syaikh Ahmad al-Mutamakkin juga pernah dikaji oleh Islah dalam kajian tasawuf. Ia membahas tentang pemikiran tasawuf Syekh Mutamakkin dengan mengacu pada teks "Arsh al-Muwahhidīn". Teks tersebut berisi petunjuk tentang ibadah salat dengan perspektif fiqh dan tasawuf. 12

Ketiga, resolusi konflik pertentangan agama antara Syaikh Ahmad alMutamakkin dan ulama-ulama struktural pada masa kerajaan Mataram Islam juga pernah diteliti oleh M. Muslich dengan bersandar pada kandungan isi teks Kajen dan Serat Cebolek. Kedua isi teks yang saling bertentangan tersebut diperbandingkan isinya serta dicari jalan tengahnya dengan mengedapankan prosesi resolusi konflik dengan paradigma Islam. Untuk menyelesaikan konflik

\footnotetext{
${ }^{10 S y u k u r, ~ T a s a w u f S o s i a l, ~} 178$.

${ }^{11}$ Muzairi Muzairi, "Pembangkangan Mistik Jawa dalam Suluk Cebolek (Episode Haji Ahmad Mutamakin)," Esensia: Jurnal Ilmu-ilmu Ushuluddin 12, no. 1 (2011): 21-38, https://doi.org/ 10.14421/esensia.v12i1.700.

${ }^{12}$ Islah Gusmian, "Pemikiran Tasawuf Syekh Ahmad Mutamakkin: Kajian Hermeneutik atas Naskah 'Arsy al-Muwahhidin,” Jurnal Lektur Keagamaan 11, no. 1 (2013): 57-90, https://doi.org/ 10.31291/JLK.V11I1.52.
} 
ini pihak penguasa dari kerajaan Mataram Islam mengutus Patih Danurejo dan Raden Demang Urawan sebagai mediator penyelesaian konflik tersebut. Berkat kepiawaian Patih Danurejo dan Demang Urawan dalam melakukan tugas negara dihasilkan resolusi konflik yang memuaskan semua pihak. Pelajaran berharga yang dapat diambil dalam persoalan ini dapat menjadi model pembelajaran bahwa penyelesaian suatu konflik tidak harus berujung pada pemberian hukuman, tetapi menekankan kepada dialog dan penyadaran di luar sidang pengadilan. 13

Keempat, mengungkap makna ziarah di makam Syaikh Ahmad alMutamakkin Kajen juga pernah dikaji oleh A.H. Choiron (2017) dalam perspektif konseling tasawuf. Ia mengungkap makna mendalam yang terkandung di balik pelaksanaan ziarah di makam Syaikh Ahmad al-Mutamakkin di Kajen Pati, terutama yang berkaitan dengan makna ajaran sufisme. ${ }^{14}$

Kajian yang dilakukan terhadap pelbagai hasil penelitian di atas menghasilkan beberapa kesimpulan. Pertama, berbagai hasil penelitian sebelumnya menganggap pemikiran tasawuf Syaikh Ahmad al-Mutamakkin bukan sebagai kritik atas kesewenang-wenangan elit politik dalam menghegemoni agama rakyat. Kedua, penelitian ini ditujukan untuk membuka paradigma berfikir Syaikh Ahmad al-Mutamakkin sebagai seorang neo-sufisme yang mencoba mendobrak hegemoni elit politik melalui kritik epistemologi dalam pemikiran tasawufnya.

Metode penelitian yang digunakan dalam penelitian ini adalah metode historis dengan pendekatan hermeneutika. ${ }^{15}$ Pendekatan hermeneutika digunakan karena sumber sumber primer yang digunakan berasal dari teks sastra, yang umumnya berisi kiasan dan makna simbolik. Setiap model interpretasi (hermeneutika) adalah upaya untuk membongkar makna-makna yang masih terselubung dalam sebuah karya sastra. ${ }^{16}$ Oleh karenanya dalam setiap

${ }^{13}$ M. Muslich, "Resolusi Konflik kasus Syaikh al-Mutamakkin dalam Teks Kajen dan Serat Cebolek," Al-Tahrir: Jurnal Pemikiran Islam 15, no. 1 (2015): 159-77, https://doi.org/10.21154/altahrir.v15i1.174.

${ }^{14}$ A.H. Choiron, "Menggali Makna Ziarah di Makam Toriqoh Syaikh Ahmad al-Mutamakkin Kajen dalam Perspektif Konseling Tasawuf," Konseling Religi: Jurnal Bimbingan Konseling Islam 8, no. 1 (2017): 1-26, https://doi.org/10.21043/kr.v8i1.2268.

15 Kuntowijoyo, Metodologi Sejarah (Yogyakarta: Tiara Wacana Yogya, 2003), 10-12.

16Paul Ricoer secara sitematis dan metodis menunjukkan bagaimana manusia bertolak dari interpretasi sebuah teks untuk sampai kepada interpretasi eksistensi manusia dalam kandungan isi sebuah teks. Oleh karenanya, Ricoer merumuskan dua pokok teori hermeneutika, yakni teori teks dan kisah sebagai model transformasi kreatif. Lihat: Paul Ricoeur, Hermenutika Kontemporer, ed. 
penelitian yang bersumber pada teks sastra, maka diperlukan upaya penafsiran yang mampu melihat sesuatu yang kabur, jauh, dan gelap maknanya menjadi sesuatu yang jelas, dekat, dan dapat dipahami. Dalam konteks inilah sesungguhnya pendekatan hermeneutika ditempatkan, mengingat penulisan teks sastra mayoritas didominasi oleh penggunaan bahasa simbolik yang terdiri atas lipatan dan tingkatan makna.

\section{B. Riwayat Kehidupan dan Silsilah Syaikh Ahmad al-Mutamakkin}

Syaikh Ahmad al-Mutamakkin merupakan seorang ulama sufi yang menyebarluaskan risalah Islam di wilayah pantai utara Jawa dan sekitarnya. Dalam local history setempat Syaikh Ahmad al-Mutamakkin juga diingat dengan nama Syaikh Cebolek. ${ }^{17}$ Sebagai seorang guru fiqih, beliau sangat disegani oleh para pengikutnya karena berpandangan jauh dan luas. Oleh sebab itu, sebutan mahaguru dalam bidang keagamaan disematkan oleh para pengikutnya kepada Syaikh Ahmad al-Mutamakkin. Dalam mendidik intelektualitas keagamaan murid-muridnya, beliau merintis berdirinya pondok pesantren di Kajen. Dengan membuka pondok pesantren sebagai lapangan pendidikan Islam diharapkan mampu mencetak mubaligh dan kader-kader agama yang nantinya akan menyambung tali perjuangan beliau. 18

Selaku ulama serta guru besar agama, beliau juga kerap melakukan melakukan rihlah untuk berdakwah ke berbagai wilyah sesuai arah dan murat dari khitah Islamisasi terhadap masyarakat Jawa. Terhitung sejak dasawarsa kedua abad XVIII, beliau menyebarluaskan risalah Islam dari Desa Cebolek, yang berada di Tuban menuju ke arah barat, sampai ke Desa Kalipang, yang terletak di Kecamatan Sarang Kabupaten Rembang. ${ }^{19}$ Disana beliau menetap beberapa lama dan sempat mendirikan sebuah masjid. Setelah itu, beliau meneruskan rihlah sampai ke Cebolek, sebuah Desa di kecamatan Margoyoso Kabupaten Pati Jawa Tengah. Ketika itu wilayah Cebolek masih bagian dari Kecamatan Juwana.

Josef Bleicher. terj. Ahmad Norma Permata (Yogyakarta: Fajar Pustaka, 2003), 45; Lathifatul Izzah elMahdi, "Hermeneutika-Fenomenologi Paul Ricoeur: Dari Pembacaan Simbol Hingga Pembacaan Teks-Aksi-Sejarah," Hermeneia, Jurnal Kajian Islam Interdisipliner 6, no. 1 (2007): 17-42, http:// digilib.uin-suka.ac.id/8508/.

${ }^{17}$ Local history masyarakat Desa Kajen seluruhnya terrmuat dalam isi Teks Kajen.

${ }^{18}$ K.H. Thohir Muadz, wawancara, 8 Maret 2018.

${ }^{19}$ Kandito Argawi, Syekh Mutamakkin: Perjalanan Hidup, Pendakian Spiritual, dan Buah Pikir Emas Sang Legenda Tanah Jawa (Yogyakarta: LKiS, 2013), 90. 
Setelah bermukim di Cebolek beberapa lama, beliau kemudian hijrah ke Desa Kajen sampai akhir hayatnya.

Banyak masyarakat di sekitar pusaran Syaikh Ahmad al-Mutamakkin menganggap bahwa, beliau bukan orang biasa melainkan ialah seorang wāliyullāh yang memiliki pengaruh dalam kehidupan agama, sosial, dan kebudayaan dalam tataran kultural. Keterangan ini setidaknya termakhtub dalam beberapa versi sumber sejarah yang menjabarkan mengenai silsilah Syaikh Ahmad Mutamakkin. Menurut mendiang K.H. Abdurrahman Wahid (Gus Dur), silsilah Syaikh Ahmad al-Mutamakkin berasal dari Persia (Zabul) Propinsi Krasan, Iran selatan..$^{20}$ Mendiang K.H. Abdurrahman Wahid juga pernah mengatakan dalam sebuah kesempatan saat dirinya berkunjung ke Kajen bahwa, Syaikh Ahmad al-Mutamakkin masih merupakan leluhurnya. ${ }^{21}$ Dalam kesempatan tersebut K.H. Abdurrahman Wahid menceritakan tentang pendekatan kultural yang selama ini ia gunakan untuk melawan rezim otoritarian orde baru memang hampir seluruhnya mengadopsi dari pendekatan serupa yang digunakan Syaikh Ahmad al-Mutamakkin dalam melawan kesewenangan elit penguasa.

Sumber sejarah versi berikutnya yang cukup dikenal masyarakat setempat adalah penuturan mengenai asal usul Syaikh Ahmad al-Mutamakkin yang merupakan keturunan dari bangsawan Jawa. Versi ini sendiri mengutip dari penuturan turun-temurun masyarakat sekitar yang bersumber dari local history setempat Keberadaan local history yang dimaksud ialah Teks Kajen. Didalamnya dijelaskan secara terperinci mengenai silsilah Syaikh Ahmad al-Mutamakkin dari leluhurnya yang merupakan bangsawan Jawa. Syaikh Ahmad al-Mutamakkin merupakan keturunan Raden Patah (Raja Demak, Sultan Bintoro). Silsilah Syaikh Ahmad al-Mutamakkin berada melalui Sultan Trenggono. Sultan Trenggono mempunyai empat orang anak, yaitu Putri Sekar Taji, Sunan Prawoto (Raden Bagus Mukmin), Ratu Kalinyamat (istri pangeran Hadirin, Jepara) dan putri istri Pangeran Timur di Madiun. Putri Sekar Taji ini dinikahi Jaka Tingkir (Sultan Pajang, Sultan Hadiwijaya). Dari pernikahan ini lahir anak bernama

${ }^{20}$ K.H. Abdurrahman Wahid, "Syekh Ahmad Mutamakkin," Republika.co.id (30 Agustus, 2009), https://www.republika.co.id/berita//no-channel/09/08/30/72742-syekh-ahmad-mutamakkin.

${ }^{21}$ K.H. Abdurrahman Wahid, "Saat Gus Dur 'Gagal' Bertemu Mbah Mutamakkin di Alam Kubur,” NU Online (5 Februari, 2018), http://www.nu.or.id/post/read/86200/saat-gus-dur-gagalbertemu-mbah-mutamakkin-di-alam-kubur. 
Sumahadiningrat (Sunan Benawa I). Sunan Benawa I ini mempunyai putra bernama Sumahadinegara (Sunan Benawa II). Perkawinan antara Sunan Benawa II dengan Putri Raden Tanu melahirkan Sumahadiwijaya alias Syaikh Ahmad Mutamakkin.22

Selain memiliki trah seorang bangsawan Jawa, ternyata masyarakat setempat juga masih mempercayai bahwa Syaikh Ahmad al-Mutamakkin juga mempunyai garis keturunan langsung dari Nabi Muhammad. Silsilah Syaikh Ahmad al-Mutamakkin menunjukkan pertemuanya dengan Rasulullah melalui garis; al-Mutamakkin ibn Sumahadinegara ibn Sunan Benawa ibn Abdurrahman Basyaiban ibn Sayyid Umar ibn Sayyid Muhammad ibn Sayyid Ahmad ibn Sayyid Abu Bakar Basyaiban ibn Sayyid Muhammad Asadullah ibn Sayyid Husain al-Turaby ibn Sayyid 'Aly ibn Sayyid Muhammad Shahib al Murbath ibn Sayyid 'Aly Khaly' Qasim ibn Sayyid Alwy ibn Sayyid Muhammad ibn Sayyid Alwy ibn Imam 'Ubaidullah ibn Imam Ahmad al-Muhajir ila Allah ibn Imam 'Isa an Naqib ibn Imam Muhammad an Naqib ibn Imam Alwy al Uraidhi ibn Imam Ja'far Shodiq ibn Imam Muhammad al-Baqir ibn Imam Ali Zainal Abidin ibn Sayyidina Husain ibn Fatimah al-Zahra binti Sayyidina Muhammad. ${ }^{23}$

Ada perbedaan mengenai versi silsilah yang lain pada tingkat Sayyid 'Alwy ke bawah. Pada silsilah ini, al-Mutamakkin ibn Sumahadinegara ibn Sunan Benawa ibn putri Sultan Trenggono binti Sultan Trenggono ibn Istri Raden Patah binti Maulana Rahmat ibn Maulana Ibrahim ibn Jamauldin Husaen ibn Sayyid Ahmad Syah ibn Sayyid 'Abdullah ibn Sayyid Amir Abd al-Malik ibn Sayyid 'Alwy, dan seterusnya seperti silsilah di atas. ${ }^{24}$

Penjabaran sekilas mengenai riwayat kehidupan dan beberapa versi sejarah tentang silsilah dari Syaikh Ahmad al-Mutamakkin memang sangat menarik untuk dikaji secara mendalam. Dalam perspektif penulis, silsilah Syaikh Ahmad al-Mutamakkin kemudian menjadi semacam inspirasi bagi banyak khalayak luas, utamanya yang bagi yang memiliki basis pendidikan pesantren. Ulama-ulama setelahnya, serta kyai dan para santri yang berafiliasi dengan dunia pesantren menjadikan kisah perjuangan Syaikh Ahmad al-Mutamakkin, sebagai rujukan dan inspirasi untuk mengkonstruksi ulang sejarah ulama dan genealogi keilmuwan orang-orang pesantren.

22Bizawie, Syekh Mutamakkin: Perlawanan Kultural Agama Rakyat, 117.

23Bizawie, 119.

24Bizawie, 120. 


\section{Genealogi Intelektual Syaikh Ahmad al-Mutamakkin}

Syaikh Ahmad al-Mutamakkin adalah salah satu waliyullah yang cukup eklektik dan konformis dalam memperkenalkan keluhuran ajaran Islam. ${ }^{25}$ Kesadaran Syaikh Ahmad al-Mutamakkin akan realitas kehidupan sosial budaya masyarakat Jawa serta upayanya untuk membaurkan keduanya pada abad XVIII menjadi contoh konkrit pemikiran eklektik yang dimilikanya. Sebagai ulama yang dikaruniai keahlian agama dan kesalehan sosial tentu beliau sadar jika masyarakat Jawa sulit menerima pengaruh islam jika masih mempertahankan metode islamisasi yang tidak eklektik. Sebab dalam realita kala itu menunjukkan, bahwa corak kebudayaan peninggalan peradaban animisme, dinamisme dan hindu-buddha masih mengakar kuat pada diri masyarakat Jawa. ${ }^{26}$ Pemahaman tersebut mengindikasikan bahwa keberhasilan Islamisasi di Jawa tergantung pada mampu atau tidaknya mewujudkan strategi islamisasi yang dapat mengakomodir tradisi dan budaya lokal (Jawa).

Pemikiran-pemikiran eklektik dan konformis dalam mendakwahkan syiar Islam seperti yang dimiliki waliyullah sekaliber Syaikh Ahmad al-Mutamakkin tentu tidak lahir secara instan. Sebagai seorang ulama yang mengajarkan sufisme (tasawuf), Syaikh Ahmad al-Mutamakkin selalu menempatkan ajaran Islam sebagai pembuka serambi peradaban sekaligus landasan etis pembangunan manusia yang berbudi luhur (insan kamil). Paling tidak, didalam pemikiran eklektik tersebut tersemat pesan dari Hadratus Syaikh yang menjadi guru maupun panutan Syaikh Ahmad Mutamakkin.27 Oleh sebab itu penelusuran tentang jejak rihlah ilmiah serta genealogi keilmuan akan sangat berperan dalam menentukan paham keagamaan yang dikembangkan Syaikh Ahmad Mutamakkin. Dari keterangan yang diperoleh dari Serat Cebolek, menunjukkan bahwa guru intelektual Syaikh Ahmad al-Mutamakkin ialah Syaikh Zayn al-

${ }^{25}$ Yang dimaksud "eklektik" ialah bersifat memilih yang terbaik dari berbagai sumber (tentang orang, gaya, metode). Sedangkan yang dimaksud "konformis" adalah saat individu mengubah sikap dan tingkah lakunya agar sesuai dengan norma sosial yang ada . dengan kata lain, dalam setiap dakwahnya Syaikh Ahmad al-Mutamakkin selalu menempatkan al-Qur'an dan Hadis sebagai rujukan utama yang harus diyakini umat Islam, tanpa membenturkanya dengan tradisi dan budaya lokal setempat. Lihat: Soebardi, The Book of Cabolek, 120.

${ }^{26}$ Manggara Bagus Satriya Wijaya, "Kontribusi Syekh Ahmad Mutamakkin dalam proses Islamisasi di Jawa (Studi Kualitatif tentang Teks Kajen)," Jantra 12, no. 2 (2017): 1-17, http://www.pustaka-bpnbkalbar.org/pustaka/jantra-vol-12-no-2-desember-2017.

${ }^{27}$ Sosok guru yang dimaksud, ialah Syaikh Zayn al Mizjaji al-Yamani.

JURNAL THEOLOGIA — Volume 29, Nomor 2, Desember 2018 
Mizjaji al-Yamani. Peristiwa ini terungkap jelas dari pengakuan Syaikh Ahmad al-Mutamakkin dalam Serat Cebolek pupuh VII Gambuh bait 5 dan 6, sebagai berikut: $^{28}$

Pinurugan yen dalu / mring Raden Demang anunggal laku / pinrih wutah sabarang kawruhireki / Ki Cabolek kawruhipun:/ "wite angantepi kawroh neng Yaman angeguru / Seh Jen kang mangka paguronipun, / daerahe angblegi Dewaruci / keh Dewaruci kedhaton.

(Setiap malam, ia didatangi/oleh Dyan Demang, yang setiap kali pergi (mengunjunginya)/ meminta dia untuk mempertunjukkan semua ilmunya /Ki Cabolek berkata:/ "pertama kali saya memeluk ajaran mistik di Yaman, waktu saya belajar/ di bawah seorang guru (pendidik), yang namanya Ki Syaikh Zain / ajaran yang diberikan sama dengan Dewa Ruci).

Secara transparan, penggalan Serat Cebolek pada pupuh VII Gambuh bait 5 dan 6 tersebut mengisahkan pengakuan Syaikh Ahmad al-Mutamakkin tentang genealogi keilmuanya. Syaikh Ahmad al-Mutamakkin menjelaskan kepada Raden Demang Urawan (utusan Kerajaan Mataram) mengenai sosok guru dan ajaran seperti apa yang diberikan bagi dirinya. Saat melaukan perjalanan (rihlah) menuntut ilmu ke Yaman kepada Syaikh Zayn al-Mizjaji al-Yamani, dirinya diberikan ajaran yang memiliki kemiripan dengan teks Bimasuci. Dari keterangan Syaikh Ahmad al-Mutamakkin tersebut mengisyaratkan bahwa figur Syaikh Zayn al-Mizjaji al-Yamani lewat ajaranya dapat dikategorikan sebagai salah satu tokoh sufi. Dalam paradigma pemikiran seorang sufi penggunaan semacam teks Bimasuci dan sejenisnya merupakan upaya untuk semakin menyadari betapa pentingya jalan esoteris (haqiqah) untuk menunjang jalan eksoteris (sharīat) dalam mentransmisikan ajaran islam kepada diri seseorang, sehingga dalam dirinya terpancar moralitas dan penghayatan ajaran islam secara mendalam. ${ }^{29}$ Figur Syaikh Zayn al-Mizjaji al-Yamani juga dikenal oleh masyarakat sekitar pusaran Syaikh Ahmad al-Mutamakkin. Figur Syaikh Zayn alMizjaji al-Yamani sendiri merupakan tokoh historis dalam hasil penelitian Azyumardi Azra mengenai jaringan ulama. ${ }^{30}$ Pendapat senada juga telah diuji

${ }^{28}$ Isi Serat Cebolek menggambarkan dinamika 'pedalaman-pesisiran' yang sarat dengan nuansa politis. Meski begitu, agaknya apa yang tertulis dalam Serat Cebolek pada pupuh gambuh bait 5 dan 6 relevan dengan tujuan untuk menelusuri lebih lanjut genealogi keilmuwan ulama Jawa lain yang mungkin bersama-sama Syaikh Ahmad Al-Mutamakkin melakukan rihlah ilmiah di Yaman. 1999), 89.

${ }^{29}$ R. Mark Woodward, Islam Jawa: Kesalehan Normatif Versus Kebatinan (Yogyakarta: LKiS,

${ }^{30}$ Azyumardi Azra, Jaringan Ulama Timur Tengah dan Kepulauan Nusantara Abad XVII dan XVIII (Edisi Perenial) (Jakarta: Kencana, 2014), 123. 
keotentikanya oleh M.C. Ricklefs dalam mahakaryanya bertajuk The Seen and The Unseen Worlds in Java 1726-1749. Dengan demikian, figur Syaikh Zayn alMizjaji al-Yamani dapat dikatakan sebagai seorang tokoh ulama besar yang menjadi guru bagi para ulama muslim nusantara yang melakukan rihlah ilmiah dalam periode awal abad XVIII.

Mengenai waktu Syaikh Ahmad al-Mutamakkin mengadakan rihlah ilmiah ke negeri Yaman sampai periode berguru pada Syaikh Zayn al-Mizjaji al-Yamani sayangnya tidak bisa diketahui secara pasti. Baik kitab 'Arsh al-Muwahhidīn, teks Kajen, serta manuskrip Serat Cebolek tidak menerangkan secara terperinci mengenai waktu Syaikh Ahmad al-Mutamakkin mengadakan rihlah ilmiah. Meski begitu, kontribusi Syaikh Ahmad al-Mutamakkin dalam menjernihkan Islam Jawa dalam perspektif ketauhidan sangatlah penting. Kritik tajamnya lewat perlawanan kultural terhadap hegemoni konsep raja-sufi semata-mata ditujukan, untuk mempertanyakan dan mengkritisi landasan epistemologis konsep ajaran sufisme yang dikembangkan pihak keraton. Menurut Syaikh Ahmad al-Mutamakkin ajaran sufisme yang dikembangkan oleh elit keraton sudah tidak relevan dengan syariah, karena telah digunakan untuk mereproduksi khazanah keagamaan pra Islam yang bersifat pantheistis. Hal ini tentu sangat kontradiktif dengan makna harfiah dari sufisme yang sejatinya merupakan bagian dari kerangka ajaran islam, yakni sebagai entitas dari iḥsān.

\section{Pemikiran Neo-Sufisme Syaikh Ahmad al-Mutamakkin}

Istilah "neo-sufisme" sejatinya bukanlah sesuatu yang sepenuhnya baru dalam sejarah pemikiran Islam. Menurut Fazlur Rahman, neo-sufisme adalah sufisme yang telah diperbaharui (reformed siffism). Dalam sejarah pemikiran Islam, keberadaan neo-sufisme sendiri memang selalu dipertentangkan di kalangan pengikut sufisme. ${ }^{31}$ Para pengikut sufisme lama tidak menafikan, bahwa keberadaan gerakan neo-sufisme sesungguhnya telah memporakporandakan pemahaman teologis mereka. Sementara perspektif berbeda diyakini oleh kalangan neo-sufisme. Mereka menganggap, bahwa keberadaanya merupakan antitesa terhadap beberapa kasus penyimpangan pendukung sufisme lama yang dalam beberapa aspek tertentu sudah tidak sejalan dengan syari'at Islam. Dengan karakteristik tersebut, maka dalam perkembangan lebih lanjut pemikiran neo-sufisme telah menjadi dasar bagi berbagai gerakan

31Fazlur Rahman, Islam (New York: The Chicago University Press, 1979), 78.

JURNAL THEOLOGIA — Volume 29, Nomor 2, Desember 2018 
pembaharuan, baik yang bersifat damai maupun radikal di segenap penjuru dunia muslim.

Gerakan pembaharuan yang didengungkan oleh para neo-sufisme sejak abad XVIII, pada akhirnya sampai ke Jawa melalui ulama-ulama lokal yang telah selesai menunaikan rihlah ilmiah dari segenap penjuru dunia muslim. Salah satu ulama Jawa yang telah selesai melakukan rihlah tersebut, ialah Syaikh Ahmad alMutamakkin. Seorang ulama yang memiliki garis keturunan bangsawan Jawa, yang sejak periode akhir abad XVII hingga awal abad XVIII menetap serta berguru pada sosok ulama besar Haramyn, yakni Syaikh Zayn al-Mizjaji alYamani. Masa al-Mutamakkin melakukan rihlah bersamaan dengan terjadinya reformasi pemikiran para ulama Haramyn, yang kala itu mulai menyadari semakin pentingnya jalan esoteris (haqiqah). Menurut Zainul Milal Bizawie, kesadaran para ulama Haramyn tentang pentingnya eksistensi dimensi esoteris disebabkan kemunculan-kemunculan tarekat-tarekat baru yang bermunculan, misalnya tarekat yang dibawa oleh para ulama asal India. ${ }^{32}$ Dari genealogi intelektualnya dapat diasumsikan, bahwa Syaikh Ahmad al-Mutamakkin termasuk golongan ulama neo-sufisme awal yang ada di Jawa. Ini diperkuat dengan catatan-catatan keagamaanya yang banyak mengutip hadis-hadis dalam menjelaskan paham keagamaanya. ${ }^{33} \mathrm{Hal}$ ini tidak mengherankan, sebab tradisi yang berkembang di kalangan ulama neo-sufisme adalah sangat selektif dalam mengkaji sebuah hadis, atau dengan kata lain ia hanya menerima isnad terpercaya (uluw al-isnad atau al-isnad al-'aly).

Dalam setiap prosesi dakwahnya Syaikh Ahmad al-Mutamakkin selalu menganjurkan, agar masyarakat muslim selalu meninggalkan kemalasan dan kebodohan dengan menggunakan waktu untuk tujuan-tujuan yang bermanfaat. Ia juga menegaskan agar masyarakat muslim menjalankan tugas-tugas keduniaan untuk mencapai pemenuhan spiritual. Hal ini sejalan dengan pendapat Azyumardi yang menilai, bahwa ulama-ulama neo-sufisme biasanya tidak hanya menekankan aktvitas intelektual, tetapi juga aktivisme yang lebih praktis. ${ }^{34}$

\footnotetext{
32Kedatangan tarekat-tarekat yang dibawa ulama India telah menghasilkan, interaksi, reapprochment, dan rekonsiliasi lebih intens diantara ulama sufi dengan ulama fiqh yang menekankan jalan eksoteris (syariat). Lihat: Bizawie, Syekh Mutamakkin, 128.

${ }^{33}$ Catatan yang dimaksud ialah kitab 'Arsh al-Muwāhidīn, yang isinya banyak menerangkan mengenai pemikiran-pemikran tasawuf al-Mutamakkin.

${ }^{34}$ Azra, Jaringan Ulama, 189.
} 
Menghadapi realitas saat itu, dimana banyak terjadi penyimpanganpenyimpangan praktik keagamaan, baik yang dilakukan elit politik maupun elit agama, membuat Syaikh Ahmad al-Mutamakkin terdorong untuk melakukan reorientasi pemahaman keagamaan, khususnya bagi para ulama sufi yang ada di jajaran struktural. Dalam pemikiranya, ulama sufi yang berafiliasi dengan penguasa (struktural) kurang bersikap kritis atas diberlakukanya konsep rajasufi, yang didalamnya banyak terjadi penyimpangan-penyimpangan ajaran sufisme. Akibatnya masyarakat terjebak dalam pemahaman sempit, yang mengharuskan mereka bersikap pasif terhadap segala ketentuan yang dibuat elit politk, karena ulama di sekelilingnya pun juga menganjurkan demikian. Menurut Syaikh Ahmad al-Mutamakkin, tidak seharusnya seorang sufi bersikap apatis dan pasif terhadap persoalan di sekililingnya. Sufi yang sebenarnya bukanlah sufi yang mengalienasikan diri dari masyarakat, melainkan sufi yang menyeru pada kebaikan dan mencegah kemungkaran, membantu orang sakit dan miskin, dan membebaskan mereka yang tertindas. Seorang sufi juga dituntut, untuk melakukan ta'awwun (tolong menolong) dengan muslim lain, dalam rangka menyongsong terciptanya kemaslahatan umat. Inilah beberapa contoh yang harus dilakukan oleh setiap sufi, untuk menjadi manusia sempurna (al-insān al-kāmil). ${ }^{35}$

Syaikh Ahmad al-Mutamakkin juga menegaskan, bahwa yang dimaksud manusia sempurna (al-insān al-kāmil) bukan hanya berkutat pada tataran pengetahuan esoteris yang mendalam, melainkan juga harus membekali dirinya sendiri dengan pengetahuan eksoteris yang memadai. Hal ini terlihat dari catatan-catatan di tulisan sehari-harinya (kitab 'Arsh al-Muwahhịidin) yang menunjukkan, bahwa secara keseluruhan ajaran Islam dapat disistematikan menjadi tiga, yakni Imān, Islām, dan Ihsān. Dari tiga konstruksi bangunan ajaran islam tersebut, yang paling asasi adalah akidah. Akidah menjadi dasar untuk berperilaku bagi setiap muslim, sebab dengan akidah seseorang akan meyakini adanya Dzat Yang Mahakuasa dan Maha Mengetahui. Al-Mutamakkin juga merinci secara jelas dalam tulisanya, bahwa tujuan yang ingin dicapai akidah (berintikan tawhīd) dan ibadah (arkānu al-Islām) ialah, untuk pembinaan akhlak seseorang dan masyarakat, baik akhlak vertikal maupun akhlak Horizontal. ${ }^{36}$ Ia juga menganalogikan, tentang hubungan iman dengan ibadah, serta akhlak bagaikan pohon dengan akarnya. Dengan kata lain, jika seseorang telah berhasil

${ }^{35} \mathrm{Azra}, 201$.

36Syaikh Ahmad Mutamakkin, "Arsy al-Muwahiddin," dalam Bizawie, Syekh Mutamakkin, 298.

JURNAL THEOLOGIA — Volume 29, Nomor 2, Desember 2018 
meraih ketiganya (Imān, Islām, dan Ihsān), maka dirinya pantas disebut sebagai al-insān al-kāmil, yang bersumber dari Nūr Muhammad dan merupakan penjelmaan tajalli Dzat dan Asmä' Allah.

\section{E. Perlawanan Kultural Syaikh Ahmad al-Mutamakkin terhadap Hegemoni Agama Keraton}

Kondisi sosio kultural yang terjadi pada peralihan abad ke XVII dan ke XVIII di pusat peradaban Islam telah membentuk corak keberagaman dalam dunia muslim. hal ini tampak jelas dari upaya para ulama sufi untuk melakukan revitalisasi terhadap keberadaan ajaran sufisme. Dalam konteks sosio-kultural tersebut, Syaikh Ahmad al-Mutamakkin kemudian mengambil peranya, sebagai agen revitalisasi di tanah Jawa. Seperti yang dialami para pengembang neosufisme lainya, al-Mutamakkin harus menghadapi kenyataan, bahwa dirinya harus berhadapan dengan ulama-ulama birokrat yang berada di lingkungan kekuasaan. Dewan ulama keraton, yang kala itu dipimpin Ketib Anom Kudus merasa, bahwa ajaran yang dibawa al-Mutamakkin bersifat heretic (menyimpang). Inilah sejatinya, yang menjadi pangkal permasalahan antara kedua belah pihak, sehingga menimbulkan terjadinya pertentangan paham keagamaan, seperti yang tertulis dalam naskah Jawa klasik, Serat Cebolek ${ }^{37}$

Pertentangan paham keagamaan yang termaktub dalam Serat Cebolek mirip, dengan apa yang terjadi dalam sejarah pemikiran Islam, yakni disebabkan adanya unsur pergumulan antara pemikiran sufisme dan neo-sufisme yang sebelumnya mengemuka. Peristiwa pertentangan paham keagamaan antara pengikut sufisme dan neo-sufisme selama ini memang berkutat pada tataran epistemologis, yang menjadi landasan utama keyakinan kedua belah pihak. Keberedaan neo-sufisme, sebagai gerakan pembaharuan telah mengikis kerangka epistemologis, yang selama ini menjadi acuan para pengikut sufisme konvensional. Mengenai latar belakang, serta tujuan terbentuknya gerakan neosufisme, hingga menjadi sebuah gerakan antitesa dari sufisme konvensional. Riset Fazlur Rahman tentang neo-sufisme, dapat dijadikan sebagai acuan primer

\footnotetext{
${ }^{37}$ Manuskrip Serat Cebolek adalah salah satu karya sastra bersejarah yang dihasilkan oleh Raden Ngabehi Yasadipura I, sebagai pujangga kerajaan kala itu. Di dalamnya banyak memuat seputar pertentangan agama yang melibatkan Syaikh Ahmad Mutamakkin dengan ulama-ulama di tataran struktural. Serat ini digubah sebelum terjadinya peristiwa palihan nagari pada pertengahan abad XVIII atau sezaman dengan keberadaan Kasunanan Kartasura. Lihat pupuh VII (Gambuh) dalam Raden Ngabehi Yasadipura I, Serat Cebolek (Jakarta: Proyek Penerbitan Buku Sastra Indonesia dan Daerah, 1981), 86.
} 
dalam proses penelaahan. Fazlur Rahman menekankan, bahwa sebagian besar sifat ekstatik, metafisis, dan kandungan mystiko-filosofis yang sebelumnya begitu dominan dalam sufisme kini keberadaanya digantikan kandungan yang tidak lain daripada postulat-postulat agama (Islam) ortodoks. ${ }^{38}$ Dengan kata lain pendapat Fazlur Rahman tersebut menguraikan lebih jauh, bahwa gerakan neosufisme lebih menekankan dan memperbarui faktor moral asli dalam kontrol diri puritanis, dalam sufisme dengan mengorbankan bentuk-bentuk ekstravaganza sufisme populer yang unorthodox. Dengan demikian, dalam corak keagamaanya neo-sufisme lebih mengalihkan pusat perhatianya kepada rekonstruksi sosio-moral masyarakat muslim dibandingkan, dengan kesalehan normatif masing-masing individu. Kesimpulan ini sangatlah berbeda dengan pemahaman sufisme awal, yang lebih menekankan individu daripada masyarakat.

Perlawanan yang dilakukan Syaikh Ahmad al-Mutamakkin pada masa Susuhunan Amangkurat IV hingga pemerintahan putranya (Pakubuwana II), dapat diasumsikan sebagai salah satu konflik keagamaan berskala besar, setelah peristiwa serupa yang pernah menimpa Syaikh Siti Jenar, Sunan Panggung, Syaikh Amongraga, dan juga Ki Bebeluk. ${ }^{39}$ Bedanya, jika perlawanan ulamaulama tersebut berakhir dengan hukuman mati, tetapi Syaikh Ahmad alMutamakkin tidak demikian. Menurut Ricklefs, pertentangan yang terjadi antara elit agama keraton dengan al-Mutamakkin merupakan babak baru, dari pertentangan teologis yang melibatkan pengkikut sufisme dan neo-sufisme. ${ }^{40}$ Oleh karenanya, Genealogi keilmuan Syaikh Ahmad al-Mutamakkin, sebagai seorang neo-sufisme telah melahirkan sebuah kritik keras tentang penyalahgunaan ajaran sufisme untuk kepentingan politik elit keraton. ${ }^{41}$ Menurut pandangan Syaikh Ahmad al-Mutamakkin, konsepsi politik raja-sufi yang diterapkan keraton adalah bentuk penyelewengan terhadap ajaran sufisme. Penyelewengan yang dimaksud ialah dalam konteks politik yang lebih spesifik, bahwa ajaran sufisme telah digunakan sebagai basis kemunculan diskursus politik untuk kepentingan legitimasi elit. Dengan kata lain, ajaran sufisme yang mengakui

\footnotetext{
${ }^{38}$ Perlu diketengahkan dalam tulisan ini mengenai konsep neo-sufisme, sebab ide terpenting dari neo-sufisme adalah tawazun atau keseimbangan, yaitu keseimbangan antara kehidupan dunia dan kehidupan akhirat, antara kesalihan individu dan kesalihan sosial. Lihat: Rahman, Islam, 65.

39S. Soebardi, Serat Cebolek: Kuasa, Agama, Pembebasan Pengadilan K.H. Al-Mutamakkin \& Fenomena Syaikh Siti Jenar (Yogyakarta: Nuansa, 2004), 25.

${ }^{40}$ Ricklefs, The Seen and Unseen Worlds in Java, 90.

${ }^{41}$ Ricklefs, 157.
}

JURNAL THEOLOGIA — Volume 29, Nomor 2, Desember 2018 
hubungan langsung manusia dengan Tuhan telah digunakan, sebagai dasar legitimasi keagamaan bagi kekuasaan seorang raja, khususnya dalam upaya memperkuat kebesaran serta klaim-klaim supranatural seorang raja. ${ }^{42}$ Dalam realitanya peristiwa tersebut memang berlangsung di keraton Mataram pada abad XVIII, atau sezaman dengan konflik keagamaan yang melibatkan diri Syaikh Ahmad al-Mutamakkin.

Stigma ulama heretic (menyimpang), seperti yang disematkan elit politik dan elit agama keraton kepadanya telah membuat Syaikh Ahmad alMutamakkin tergerak untuk melakukan kritik epistemologis terhadap kehidupan keagamaan keraton, sekaligus kritik ideologis terhadap keberadaan konsepsi politik raja-sufi yang dinilainya sudah keluar dari keotentikan ajaran sufisme. Menurutnya, konsep politik raja-sufi telah membelenggu pemikiran masyarakat, sehingga masyarakat terjerembab dan sangat lekat dengan budaya feodalistik, yang lebih mementingkan kepentingan elit dibanding kepentingan masyarakat. Dalam tradisi feodalistik, masyarakat menganggap raja adalah satu-satunya perantara antara kehidupan makrokosmos dan mikrokosmos. ${ }^{43}$ Dengan kata lain, dalam dunia gaib dan lahir kedudukan raja diakui rakyat sebagai wakil Tuhan di muka bumi atau sebagai pemegang wewenang murba wisesa. ${ }^{44}$ Situasi demikian yang sejatinya menimbulkan kekhawatiran dalam benak Syaikh Ahmad al-Mutamakkin. Beliau menganggap konsep politik raja-sufi adalah bentuk reproduksi, atau dihidupkannya khazanah budaya pra Islam dan HinduBuddhis yang dicampur dengan ajaran sufisme. ${ }^{45}$ Oleh sebab itu, kritik epistemologis yang dilakukanya memang bertujuan untuk menata ulang konsepsi berfikir ajaran sufisme yang dikembangkan keraton.

Menurut Syaikh Ahmad al-Mutamakkin, satu-satunya cara yang bisa ditempuh ialah kembali pada pemahaman al-Qur'an dan al-Hadis, sebagai salah satu alternatif yang dapat membantu tugas tersebut. Biasanya tokoh-tokoh neosufisme seperti dirinya sangat mementingkan penggunaan hadis sebagai salah

${ }^{42}$ Ricklefs, 192.

${ }^{43}$ Makrokosmos adalah entitas dari dunia besar, yang dipersepsikan sebagai alam semseta, sedangkan Mikrokosmos ialah entitas dari dunia kecil, yang dipersepsikan sebagai manusia. Lihat: Soemarsaid Moertono, Negara dan Kekuasaan di Jawa Abad XVI-XIX (Jakarta: Gramedia, 2017), 178.

${ }^{44}$ Wewenang murba wisesa merupakan ide kekuasaan mutlak dan tertinggi, yang dalam konteks kehidupan politik kerajaan tradisonal hanya dimiliki oleh seorang raja. Moertono, 200.

${ }^{45}$ Soebardi, The Book of Cabolek a Critical Edition, 189. 
satu solusi, untuk menggali pesan-pesan moral dan sumber inspirasi dalam upaya rekonstruksi sosial kaum muslim. Dengan memegang al-Qur'an dan alHadis masyarakat diajak untuk menjauhi keberadaan sufisme keraton yang lekat dengan sikap pasivitas, serta memperkuat sifat aktivisme untuk memperoleh pertolongan eskatologis dari Tuhan. Dalam konteks perlawanan Syaikh Ahmad al-Mutamakkin, neo-sufisme telah menjadi sebuah ideologi perlawanan untuk menunjukkan bahwa perlawanan terhadap kekuasaan yang menyimpang tidak harus dilawan menggunakan kekerasan fisik, melainkan bisa dilakukan melalui cara yang lebih santun. Syaikh Ahmad al-Mutamakkin telah memberikan contoh, bahwa perlawanan kultural jauh lebih efektif dibandingkan kekerasan fisik, sebab hanya dengan memberikan kritik, tidak mengikuti kebiasan buruk penguasa, serta berusaha tampil beda dengan penguasa, yang dipersepsikan menyimpang merupakan perwujudan dari fungsi manusia sebagai agen perubahan.

Di masanya, selain disemati tuduhan heretic, Syaikh Ahmad al-Mutamakkin juga dikenal sebagai ulama yang cerdas, konformis, serta dinamis, terutama dalam pemilihan metode Islamisasi. Penggunaan cerita rakyat inspiratif yang termaktub dalam teks Bimasuci setidaknya dapat diasumsikan dalam tiga tujuan utama. ${ }^{46}$ Pertama, penggunaan teks Bimasuci merupakan sebuah gagasan dalam menepis arus besar diskursus sosial, yang cenderung berpendirian bahwa nilai budaya Jawa anti perubahan. Di sini dengan jelas ditunjukkan bahwa budaya lokal memiliki cukup referensi dalam agenda konversi keyakinan (Islamisasi).47 Kedua, pemanfaatan cerita rakyat yang ada di Jawa, seperti kisah Bimasuci, dalam memberikan pengetahuan tentang ajaran Islam khususnya ilmu hakikat merupakan strategi yang tepat pada masa itu. Tujuanya adalah agar diterima dan dihayati masyarakat dengan mudah serta tanpa mengesampingkan substansinya. ${ }^{48}$ Dengan kata lain, dari kisah inspiratif tersebut (Bimasuci) masyarakat akan menemukan suatu paradigma hidup yang realistis dan kontekstual.

Ketiga, pemikiran eklektik dan konformis Syaikh Ahmad al-Mutamakkin adalah bentuk kepekaan terhadap praktik yang bersifat kritis secara khusus sebagai konsep dalam hubungan Islam dan Kejawen. ${ }^{49}$ Proses transformasi

\footnotetext{
46Bizawie, Syekh Mutamakkin, 168.

47Bizawie, 169.

48Bizawie, 170.

${ }^{49}$ Bizawie.
}

JURNAL THEOLOGIA — Volume 29, Nomor 2, Desember 2018 
ajaran moral yang termakhtub dalam teks Bimasuci dilakukan Syaikh Ahmad alMutamakkin dengan penuh pertimbangan yang sesuai dengan pedoman Syari'ah. Dalam proses transformasi tersebut, al-Qur'an dan al-Hadis selalu menjadi pedoman utama bagi dirinya untuk merekonstruksi pemahaman sosial masyarakat. Hal ini tentu tidak berlebihan, mengingat dirinya termasuk dalam kategori pembaharu sufistik di tanah Jawa, yang mengusung paham neosufisme. Pandangan seorang neo-sufistik, selalu menghendaki penghayatan esoterisme yang mendalam, sehingga dilakukan dengan tidak mengasingkan diri atau uzlah, serta tetap aktif dalam melibatkan diri dengan masyarakat.

\section{F. Kesimpulan}

Beberapa kesimpulan telah diperoleh selama dilakukanya kajian terhadap seluruh sumber sejarah, baik yang bersifat primer maupun sumber sekunder. Kesimpulan tersebut diantaranya:

Pertama, Syaikh Ahmad al-Mutamakkin adalah seorang ulama dan kyai di tataran kultural yang turut berkontribusi besar dalam menyebarluaskan risalah Islam di wilayah pantai utara (pantura) Pulau Jawa pada dasawarsa kedua abad XVIII. Wilayah-wilayah yang menjadi tempat dakwah beliau membentang dari daerah Tuban, Rembang, hingga kemudian berakhir di Desa Kajen, Margoyoso, Pati.

Kedua, Syaikh Ahmad al-Mutamakkin adalah salah satu ulama Jawa generasi awal yang meletakkan Islam sebagai pengubah tatanan sosial kultural mapan yang opresif. Oleh sebab itu, pembaharuan pola pikir yang dibawa Syaikh Ahmad al-Mutamakkin merupakan sebuah tren gejala keagamaan, yang dalam perkembangan dunia intelektual Islam disebut sebagai neo-sufisme.

Ketiga, pemikiran neo-sufisme Syaikh Ahmad al-Mutamakkin merupakan antitesa dari ajaran sufisme, yang selama periode abad XVIII telah disalahgunakan elit penguasa kerajaan Mataram untuk meraih tujuan politik. Dalam konteks ini, pemikiran neo-sufisme menampilkan kritik epistemologi dan ideologis kepada ajaran sufisme awal yang cenderung membelenggu manusia dalam sikap pasivitas, sehingga sangat bertentangan dengan paradigma Islam sebagai agama yang meletakkan amal sosial dalam posisi sentral bagi makna keberadaan manusia.] 


\section{DAFTAR PUSTAKA}

Argawi, Kandito. Syekh Mutamakkin: Perjalanan Hidup, Pendakian Spiritual, dan Buah Pikir Emas Sang Legenda Tanah Jawa. Yogyakarta: LKIS, 2013.

Azra, Azyumardi. Jaringan Ulama Timur Tengah dan Kepulauan Nusantara Abad XVII dan XVIII (Edisi Perenial). Jakarta: Kencana, 2014.

Bizawie, Zainul Millal. Syekh Mutamakkin: Perlawanan Kultural Agama Rakyat. Jakarta: Pustaka Compass, 2014.

Choiron, A.H. "Menggali Makna Ziarah di Makam Toriqoh Syaikh Ahmad alMutamakkin Kajen dalam Perspektif Konseling Tasawuf." Konseling Religi: Jurnal Bimbingan Konseling Islam 8, no. 1 (2017): 1-26. https://doi.org/ 10.21043/kr.v8i1.2268.

Gusmian, Islah. "Pemikiran Tasawuf Syekh Ahmad Mutamakkin: Kajian Hermeneutik atas Naskah 'Arsy al-Muwahhidin." Jurnal Lektur Keagamaan 11, no. 1 (2013): 57-90. https://doi.org/10.31291/JLK.V11I1.52.

Hermansyah, Hermansyah. "Neo-sufisme (Sejarah dan Prospeknya)." Khatulistiwa 3, no. 2 (2013): 113-20. https://doi.org/10.24260/ khatulistiwa.v3i2.217.

Izzah el-Mahdi, Lathifatul. "Hermeneutika-Fenomenologi Paul Ricoeur: Dari Pembacaan Simbol hingga Pembacaan Teks-Aksi-Sejarah." Hermeneia, Jurnal Kajian Islam Interdisipliner 6, no. 1 (2007): 17-42. http://digilib.uinsuka.ac.id/8508/.

Kuntowijoyo. Metodologi Sejarah. Yogyakarta: Tiara Wacana Yogya, 2003.

Margana, Sri. Pujangga Jawa dan Bayang-bayang Kolonial. Yogyakarta: Pustaka Pelajar, 2004.

Moertono, Soemarsaid. Negara dan Kekuasaan di Jawa Abad XVI-XIX. Jakarta: Gramedia, 2017.

Muslich, M. "Resolusi Konflik kasus Syaikh Al-Mutamakkin dalam Teks Kajen dan Serat Cebolek" Al-Tahrir: Jurnal Pemikiran Islam 15, no. 1 (2015): 159-77. https://doi.org/10.21154/al-tahrir.v15i1.174.

Muzairi, Muzairi. "Pembangkangan Mistik Jawa dalam Suluk Cebolek (Episode Haji Ahmad Mutamakin)." Esensia: Jurnal Ilmu-ilmu Ushuluddin 12, no. 1 (2011):21-38. https://doi.org/10.14421/esensia.v12i1.700. 
Rahman, Fazlur. Islam. New York: The Chicago University Press, 1979.

Ricklefs, Merle Calvin. Mengislamkan Jawa: Sejarah Islamisasi di Jawa dan Penentangnya dari 1930 sampai sekarang. Jakarta: Serambi, 2013.

- - C. The Seen and Unseen Worlds in Java 1726-1749: History, Literature and Islam in the Court of Pakubuwana II. Sydney: Asian Studies Association of Australia in association with Allen \& Unwin and University of Hawaii Press, 1998.

Ricoeur, Paul. Hermenutika Kontemporer. Diedit oleh Josef Bleicher dan Ahmad Norma Permata. Yogyakarta: Fajar Pustaka, 2003.

Soebardi, S. Serat Cebolek: Kuasa, Agama, Pembebasan Pengadilan K H. AlMutamakkin \& Fenomena Syaikh Siti Jenar. Yogyakarta: Nuansa, 2004.

- - . The Book of Cabolek a Critical Edition with Introduction, Translation, and Notes: a Contribution to the Study of the Javanese Mystical Tradition. The Hague: Martinus Nijhoff, 1975.

Syukur, H.M. Amin. Tasawuf Sosial. Yogyakarta: Pustaka Pelajar, 2004.

Wahid, K. H. Abdurrahman. "Saat Gus Dur 'Gagal' Bertemu Mbah Mutamakkin di Alam Kubur." NU Online. 5 Februari, 2018. http://www.nu.or.id/post/ read/86200/saat-gus-dur-gagal-bertemu-mbah-mutamakkin-di-alamkubur.

- —_. "Syekh Ahmad Mutamakkin." Republika.co.id. Agustus, 2009. https://www.republika.co.id/berita//no-channel/09/08/30/72742syekh-ahmad-mutamakkin.

Wijaya, Manggara Bagus Satriya. "Kontribusi Syekh Ahmad Mutamakkin dalam proses Islamisasi di Jawa (Studi Kualitatif tentang Teks Kajen)." Jantra 12, no. 2 (2017): 1-17. http://www.pustaka-bpnbkalbar.org/pustaka/jantravol-12-no-2-desember-2017.

Woodward, R. Mark. Islam Jawa: Kesalehan Normatif Versus Kebatinan. Yogyakarta: LKiS, 1999.

Yasadipura I, Raden Ngabehi. Serat Cebolek. Jakarta: Proyek Penerbitan Buku Sastra Indonesia dan Daerah, 1981. 